\title{
Exploring Caregiver Perceptions of a One-to-One Tablet Program for Kindergartners
}

\author{
Tracy H. Donohue ${ }^{1}$ (I) . Fashina Aladé ${ }^{2}$
}

Accepted: 12 August 2021 / Published online: 2 September 2021

(c) The Author(s), under exclusive licence to Springer Nature B.V. 2021

\begin{abstract}
The adoption of one-to-one device programs in early childhood classrooms is a relatively new phenomenon that is quickly becoming widespread. While these devices carry potential as educational learning tools, there is still much to learn about how to successfully integrate them into classrooms and into children's lives. One important area to consider is the interplay of home and school contexts around children's device use for early learning. This focus group study sought to investigate caregivers' thoughts and perceptions of their kindergarteners' classroom-based tablet use. Participant responses revealed the complexities and nuanced challenges of navigating their children's device use both at home and in school. Caregivers conveyed a variety of perceived benefits, but also concerns and fears related to their children's device use. They expressed sentiments of trust in their children's teachers and schools, and they were eager to be shared partners who supported their children's technology use for early learning. However, they also expressed frustration at a lack of communication around school technology use, which they perceived as an obstacle to this partnership. Findings are discussed in terms of theory advancement as well as practical implications for caregivers, teachers, and school administrators.
\end{abstract}

Keywords Mobile devices $\cdot$ Tablets $\cdot$ One-to-one $\cdot$ Early childhood education $\cdot$ Caregivers $\cdot$ Home-school connection

Mobile technology use in schools has grown dramatically over the past decade. Even prior to the COVID-19 pandemic, many school districts across the United States had begun adopting one-to-one device programs, which are programs that provide mobile devices, such as tablet computers to each child (Cavanagh, 2018). These programs became even more widespread with the quick switch to remote learning brought on by the pandemic (Winther \& Byrne, 2020). As a result of the spread of one-to-one programs, children as young as kindergarten now regularly use mobile devices as learning tools in classrooms and at home. While there is great potential in tablets as early learning tools (see for example Brown, 2016; Beschorner \& Hutchison, 2013; Flewitt et al., 2015; Power et al., 2020), there is still much to uncover about

Tracy H. Donohue

donohu41@msu.edu

1 Human Development and Family Studies, Central Michigan University, 195 Ojibway Ct, Mount Pleasant, MI 48859, USA

2 Department of Advertising and Public Relations, Michigan State University, 404 Wilson Rd, East Lansing, MI 48824, USA how to maximize the benefits of young children using these relatively new tools, while mitigating any possible negative consequences.

Children's technology use does not occur in a vacuum. Recent research on technology in early education classrooms has found relationships between teachers' attitudes towards and experiences with technology and their students' learning outcomes (Blackwell, 2014; Blackwell et al., 2013, 2016; Palaiologou, 2016). Likewise, other studies have shown that parental attitudes towards technology influence children's technology use at home (Cingel \& Krcmar, 2013; Lauricella et al., 2015). However, research has largely excluded how classroom technology use impacts families, and explorations of how families may impact classroom technology use. Home-school connections are incredibly important for young children's school success (Epstein, 1987, 2018), but the home-school connection has not yet been widely considered when it comes to classroom mobile device use. Exploring caregiver perspectives and experiences with their children's mobile device use would shape a broader perspective of how school technology use impacts children. Thus, the purpose of this study was to gain a rich understanding of caregivers' perceptions of their school district's adoption 
of a one-to-one tablet program for kindergartners and how it impacted their children at school and at home.

\section{Technology in Early Grades Classrooms}

In 2012, the National Association for the Education of Young Children (NAEYC) and the Fred Rogers Center issued a joint position statement on technology use in the classroom (NAEYC \& Fred Rogers Center, 2012). Acknowledging the growing presence of technology in children's lives, the position statement encourages early childhood educators to adopt intentional technology practices in their classrooms-practices that support children's learning and development. Recommendations include providing children with choice and hands-on play to enhance learning opportunities with technology. While these recommendations provide a helpful starting point, enacting these principles is much easier said than done. In this section, we review some of the opportunities and challenges of classroom mobile device use that have been documented in recent research.

\section{Opportunities and Challenges for Instruction}

Just like any learning tool, mobile devices- which we define as any portable electronic device with Internet connectivity, such as a smartphone, tablet, or laptop- have both advantages and shortcomings. Some are inherent to the tool itself, and some are dependent on implementation. On the positive side, studies have shown that mobile device use increases students' time on task and engagement in learning activities due to instant gratification and social collaboration opportunities afforded (Beschorner \& Hutchison, 2013; Brown, 2016; Flewitt et al., 2015; Power, et al., 2020). Additionally, the flexible nature and mobility of tablets affords teachers various instructional opportunities in early childhood classrooms, such as varying instructional formats and differentiation opportunities (Beschorner \& Hutchison, 2013; Lu et al., 2017).

While the studies mentioned above show that mobile devices equip teachers and students with potential benefits, they also present challenges within classrooms. Findings suggest teachers harbor beliefs that mobile devices potentially impact children in negative ways (Palaiologou, 2016). In Palaiologou's, 2016 study, teachers expressed concerns about mobile devices making learning too passive and limiting social interaction. Another challenge teachers encounter is how to select appropriate instructional material, such as apps. Due to the availability of more than 80,000 educational apps, teachers have reported difficulties with selecting which ones to use among the "digital wild west" of apps (Guernsey et al., 2012). In addition, teachers reported spending a lot of time outside the classroom trying to identify high-quality apps to use in instruction (Flewitt et al., 2015).

\section{Opportunities and Challenges Outside the Classroom}

The NAEYC and Fred Rogers Center Statement (2012) posits that in addition to providing learning opportunities for students, technology can promote partnerships between families and schools. For example, Beschorner \& Hutchinson (2013) studied two preschool classrooms outfitted with iPads and observed that children were eager to have their teachers share their iPad work with their caregivers after completing tasks. This fostering of the home-school connection via classroom devices was, in turn, found to be motivating for the students (Beschorner \& Hutchinson, 2013).

On the other hand, there are concerns about the effects of increased screen time on child development (see for example Lissak, 2018). With caregivers already struggling to meet the widely-touted recommendation of no more than two hours of screen time per day, there is a valid question to be raised about whether schools should be adding to that total amount of screen time (Bentley, 2021). However, even the American Academy of Pediatrics, in its most recent recommendations for children's media use, acknowledged that not all screen time is created equal, and that the content and context should be carefully considered when evaluating children's screen time (Chassiakos et al., 2016). Likewise, the NAEYC and Fred Rogers position statement (2012) addresses potential developmental interference by stating, "Technology and media should not replace activities, such as creative play, real-life exploration, physical activity, outdoor experiences, conversation, and social interactions that are important for children's development" (p. 5) and encourages educators to think about how media can complement these activities instead.

\section{Addressing the Digital Divide}

School-issued devices are also often discussed as a strategy to help narrow the digital divide (Dolan, 2016). Early digital divide research showed large disparities in access to technology based on family income levels (Judge et al., 2006). Programs that provide devices to each child could be seen as digital equalizers in that sense. However, recent work citing the ubiquity of mobile devices in American homes suggests that the digital divide conversation is shifting from one about "haves and have-nots" to one about "cans and cannots," highlighting the fact that there still exist inequities in broadband access (Gao et al., 2020) and in the types of learning activities and instruction centered around mobile device use (Dolan, 2016). Herrera (2020) further describes three tiered levels of the digital divide. The first 
level includes device and internet access, the second level includes disparities in internet skills, while the third level includes varying beneficial outcomes based on differences. Herrera (2020) argues that the levels of the digital divide are underexplored and there is a need for more research in this field of study. Therefore, it is important that we continue to investigate how one-to-one programs not only impact children's access to technology, but also how having a personal device may impact their environments and the nature of their device usage.

\section{Theoretical Frameworks}

Gaining a complete understanding of the impacts of technology on early learning requires us to explore the contextual aspects of children's lives beyond classroom walls. The current study is guided by two theoretical frames pertaining to the impact of children's out-of-school contexts-specifically their time with families-on their early learning and development, namely Bronfenbrenner's bioecological theory of human development (Bronfenbrenner, 1994) and Epstein's model of overlapping spheres of families and schools (Epstein, 1987), each of which we explain briefly in this section.

Bronfenbrenner's bioecological systems theory (1994) employs a constructivist frame for understanding children's learning and development. Children's environments, as explained by this theory, are divided into the following contexts: microsystem, mesosystem, exosystem, macrosystem, and chronosystem. These contexts are nested within one another and range from a child's immediate surroundings and relationships (micro) to higher-level structures such as the political environment or world economy (macro), to the broadest of structures such as time (chrono). A meso context refers to when two of a child's micro contexts interact, such as a child's home and school interacting through a caregiver-teacher conference. Bronfenbrenner (1994) argued that teachers should consider the multiple environments in which children exist. Caregivers and families play a vital role in children's development; thus educational research that considers all of the layered contextual factors, such as their home environment and families, will provide a more complete understanding of the role technology plays in children's lives. Bronfenbrenner's theory provides the backbone and motivation for the current study; we explore the multilayered interactions between home and school environments to better understand the impact of a new one-to-one device program.

Epstein (1987) developed a theory that specifically homes in on that interaction between the family and school contexts. She describes each of a child's immediate contexts-family, school, and community - as spheres that co-exist to support children's learning, with various amounts of overlap between them. In this study, we focus on the overlap between two of the three spheres: family and school. Due to the ever-changing lives of families and the nature of schools, the degree of overlap between the family sphere and school sphere varies based on time, experiences in school, and experiences at home. Young children tend to have more overlapping spheres, with families and schools sharing more responsibilities. Epstein argues that this sharing of responsibility, this strong overlap between family and school spheres, is incredibly important for young children's success. Therefore, with a specific focus on technology adoption, this study adopts Epstein's lens of examining the overlap between home and school spheres.

Guided by these theoretical frameworks, the current study sought to explore the relationship between families and schools with regards to technology integration in classrooms. The following research questions guided data generation and analysis:

1. How do caregivers perceive their children's mobile device use in the context of a district's new adoption of a one-to-one device program?

2. In what way do caregivers believe mobile device programs have impacted their children in classrooms and at home?

\section{Modes of Inquiry}

To answer our research questions, we conducted a focus group study with caregivers of kindergartners enrolled in a district with a newly adopted one-to-one tablet program. This study was part of a larger research project examining the impact of in-school tablet use on early math and literacy skills.

\section{Participants in Context}

The participating midwestern, urban school district primarily serves low-income and minoritized children. The school district has a majority (69\%) of students labeled by the district as "economically disadvantaged." Typically, families that comprise the school district are approximately 40\% Black/African-American, 30\% White/Caucasian, and $18 \%$ Hispanic, with small percentages of Asian, Native American, and Multi-Racial families. Despite the racially and ethnically diverse make-up of the district, the caregivers who participated in this study were less diverse. Out of ten caregiver participants, seven were White and three were Black/African-American. Nine mothers and one father participated. Their children attended six of the ten district 
elementary schools. All families but one had multiple children living at home.

As researchers, we acknowledge that our backgrounds and positionalities likely shaped the focus group dynamics and our interpretation of the data. Our research team included a Black tenure-track university professor who studies children and technology and a White doctoral student who studies teacher education, who is also a caregiver and former early childhood teacher. To encourage an open, comfortable environment, we shared our personal and professional experiences in working with children with the participants. We described how we were exploring caregivers' experiences around their children's technology use and that we had nothing to gain or lose based on their comments about the tablet project. Nevertheless, we acknowledge that our positions as researchers might have influenced caregivers' willingness to be entirely frank in their discussion. We also recognize that focus groups of caregivers who came from different schools, in varying sections of the district might have felt contrived and thus might not have elicited completely natural responses.

\section{Data Generation Procedures}

As part of a larger research project, approximately one thousand kindergarteners, across an entire district, received a child-oriented educational tablet for classroom use during the school year and were then allowed to take the tablets home to keep. The local public media station and the school district collaborated to distribute the devices, serving as gatekeepers between the researchers and caregivers prior to the focus groups.

Recognizing caregivers' roles in their children's early education, we sought to document the context surrounding children's device use. Specifically, we wanted to understand caregivers' attitudes towards this new program and towards their children's mobile device use both at school and at home. First we conducted a survey, which provided a broad understanding of the media landscape in which the children in our study were engaged (Aladé \& Donohue, 2020). While informative, the survey generated additional questions for caregivers that would require more inquiry. Thus, we then conducted focus groups with a smaller subset of caregivers as a method of data generation that would allow us to gain a rich, collective perspective of caregivers' experiences of their child's tablet use for learning. A methodology based in social constructionist principles, focus group studies take into consideration that participants build upon one another's ideas while making sense of their own ideas (Wilkinson, 1998). The focus group methodology enabled us to gain "fully articulated accounts" and promoted opportunities for groups of caregivers to establish a "collective sense-making" (Wilkinson, 1998, pp. 192-193).
After receiving approval from our university's Institutional Review Board to recruit participants, we sent an email that was distributed by district administrators to all caregivers of kindergarteners in the district, inviting them to share feedback about the tablet program by participating in a focus group with university researchers. Caregivers were offered an electronic gift card as an incentive to participate. We conducted three separate focus groups at different times of the day and week to maximize convenience for our participants. Each focus group was in the summer of the second year of the study, after the children had brought home their tablets. We offered a meal at each group with the goal of creating a more relaxed and welcoming environment. Each focus group was held at a district administrative building that was roughly central to all neighborhoods in the city.

Following traditional focus group procedures (Krueger, 2014), we created a moderator's guide containing a series of questions seeking to explore caregivers' perceptions about their children's tablet use in and out of school. It contained broad questions, with additional specific sub-questions (Patton, 2002). The guide was a tool for planning the conversation, but not a script to follow verbatim. Our intent was also for caregivers to help shape the conversation with ideas we had not yet considered.

Participants agreed to be audio and video recorded and we collected this data in accordance with IRB protocol. The first author transcribed recordings from each session. Pseudonyms are used for all participants throughout this report.

\section{Data Analysis}

Systematic analysis procedures (Krueger, 2014) began with the two primary researchers and an undergraduate research assistant. We first used open coding for analysis, where we looked for themes of frequently mentioned topics, collectiveness, intensity of responses, and participant perception of importance (Krueger, 2014). Based on these inquiries, each researcher carefully read through each transcript several times, documenting a set of initial codes. Next, we reviewed our initial codes for themes and documented them on sticky notes. Then, we convened to discuss our initial codes and themes for caregivers' thoughts and perceptions on their child's tablet use. We sorted our initial themes and found the majority of them to converge. Next, we compiled the sticky note themes from each researcher and organized them based on concepts and ideas that grouped together thematically. Throughout open coding, we were receptive to any new codes for themes or ideas the caregivers presented. As the feature of sending tablets home is a fairly new action taken by schools, we entered data generation and analysis with open minds in hopes of capturing a holistic picture of caregivers' perceptions. 
Once open coding was complete, the first author used NVivo software to a priori code each transcript once again based on common themes we found in open coding. The a priori coding allowed us to group participants' comments across focus groups by theme and look for convergence or divergence in what they shared. The findings presented in the next section emerged from themes identified during data analysis.

\section{Caregivers' Perceptions Informing Classroom Tech Use}

Our analysis revealed points of consensus from the caregivers, which fell under four overarching themes: perceived benefits of the tablet program, worries and concerns about their children's technology use, lack of communication, and trust in schools and teachers.

\section{Benefits of One-to-One Programs}

Overall, caregivers shared many positive sentiments about the classroom mobile devices, both for their individual children and for kindergartners at large. Many caregivers talked about the tablets as useful learning tools. Ashlee shared she "liked the learning aspect." Sophia agreed and compared it to her own former learning experiences with computers in school. She shared, "I think there is a possibility for it to be used as a learning tool." Further, some caregivers reasoned that the tablets might help some learners more than others. When sharing his perspective, Brandon said, "I think it's good to a certain extent and also increases...opportunities in ways for the kids to learn. Because not everybody learns the same way...So, they kind of expand the scope of how you can learn too."

Collectively, caregivers touted mobile device use for learning; interestingly, some specifically described learning and fun as opposite, binary functions. For example, when discussing tablets as potential rewards, Ashlee said, "I'm okay with them being used a little bit. I understand it's a school and sometimes you expect your child to learn. But, I think a little fun on them would be okay." Furthermore, Davina, too, highlighted the binary notion by saying, "Them having something that's educational and fun. And so they're learning but it doesn't feel that way." Learning in opposition to fun was not taken up collectively, yet was mentioned by caregivers across two different sessions.

Overall, caregivers expressed excitement about the tablet program and shared that the kindergarteners were excited about having their own tablets they could use in the classroom and keep as the school year ended. When asked about their children's reactions, caregivers reported their children were "over the moon" when they spoke about them at home.
Caregivers felt that some excitement stemmed from the children's pride in ownership; children were excited to have their own device all to themselves. Rachel's son came home and said, "They're gonna give me my own tablet. And it's not going to be anyone else's tablet. Just for me. I get to use it at school. And, when I'm done I get to bring it home."

Caregivers also discussed how their initial excitement stemmed from curiosity, as this was their first experience with a kindergarten one-to-one device program. The following point by Kelly is an example of the positive perspectives expressed:

A big benefit... (is) I've seen him choose to watch shows where they're building things or inventing things. And, then he will set that aside and say, 'Mom. I need some double-sided tape. Can I remove all the toilet paper from this tube? Because I need a tube.' But, he's asking for materials and he is using them as tools or sort of as guides to create things and build things and make things. So, I love that lately it seems to have actually inspired him to walk away. And do stuff.

Kelly saw her child applying the tablet use to the real world. Camila seconded the notion of her daughter "applying things" she had learned from the tablet. Caregivers agreed this was a benefit of the device program.

Caregivers were further pleased with the district increasing access to technology for all children, especially children who otherwise might have limited access. Collectively, caregivers considered the benefits of the program to extend beyond their families. They believed the program was addressing the existing digital divide. Sophia added, "I feel like for both (the university) and for the schools that part of it is to be able to say that we know there can often be this technology gap that we know can be between urban schools and suburban schools and we're working to narrow that." Kelly reaffirmed this notion of providing digital equity by saying, "I share your sentiment that it's an interesting way to get technology into the classroom for students who may not necessarily otherwise have access at home." Caregivers did not, however, mention internet access inequities and how that may impede at-home tablet use.

\section{Caregivers' Worries, Fears, and Concerns}

Despite expressing a variety of benefits, caregivers harbored a multitude of concerns about their children's technology use. Most concerns centered around managing their children's device use. Some also mentioned potential negative impacts on their children's development.

Feelings of uncertainty on how best to support children's tablet use were consistent among caregivers. Caregivers were unsure of how to make decisions about tablet use, 
especially about time spent in front of a screen, or "screen time." For example, Sherida, whose son was allowed mostly free rein of tablet use, said, "Well, my kid's actually probably been on it too much." Rachel, who requires her children to do chores before tablet use and imposes time limits also expressed her uncertainty. She said, "And, I definitely feel a lot of guilt on days when we have a lot of screen time."

"Parent guilt" appeared to drive some caregiver uncertainty. Caregivers coupled comments about feeling guilty with their acceptance of a technology-driven world. Despite their concerns about screen time, caregivers understood the inevitability of technology in their children's lives. For example, Kelly said:

"Sometimes when I'm feeling guilty about the use of the technology, I think, 'Well, would I want my child to be where he's at or go through life being unfamiliar with these things?' Right, like, no, I wouldn't want him to get to high school and beyond and be like, 'No, I was never allowed to use those things."”

Receiving mixed messages about children's technology use also contributed to caregiver uncertainty. When asked about sources of information on screen time limits, caregivers' responses included their child's pediatricians, their own family members, and other caregivers. Rachel, for instance, mentioned that her child's pediatrician says screen time should be limited, but she is perplexed by how to balance that with school use. Rachel said:

Pediatricians say you should limit screen time. And they go to school and they use a smart board at school. And they use computers at school. And then they use the iPad at school and now they use the (tablets) at school. And you know you should limit them. Because they need no more than an hour of screen time a day. And they come home from school and they've had five hours already. And you still have to make dinner.

Peers and family members also freely shared ideas on how to supervise children's tablet use. The excerpt below highlights the nuance behind caregivers' decision making.

Moderator: (Asking about screen time)

Camila: They're being judged by other caregivers and teachers. Honestly, cause you know, you let your kids be on for a couple hours and it's like, 'Oh, you only let your child be on for two hours?' 'That's great. You're controlling it.' And then if you let your child be on all day, they're like, 'They're letting the tablet babysit their child.' And, that's not the case. It's just finding the balance and knowing when they've had too much or when they just need to take a break. Sometimes... it's just judgement for me.

Erin: I'm pretty sure the pediatrician said something.
Camila: They're very judgy people. They judge. I'll tell you that right now. Extremely judgy. Yeah.

Davina: For me, my frame of reference is typically my mom. So, I remember getting a Nintendo and it was like the best day of my life. Yeah, but they really limited the amount of time we could play. So, it's somewhere in the back of my mind. I'm like, 'Okay, you can't be on this game all day. You need to do something else with your life.'

Erin: That's true. My mom did that too.

It appears that mixed messages informed some of their decision making as well as caused confusion as to how to set limits with technology.

Caregivers were also concerned about the tablets negatively impacting their children's development. These concerns centered around two broad themes: interference with social development and displacement of traditional learning activities. In terms of the former, caregivers emphasized concern with how tablets might disrupt children's social learning. The individual nature of tablet use concerned caregivers due to their children becoming engrossed in using tablets. "Zombies" was how some caregivers described children's behavior when using tablets. Moreover, caregivers were concerned that classroom use also limits their child's social interactions. Kelly, for example, shared:

I think that when Landon uses technology I have observed that he can get very engrossed in it. So, I worry that if they rely too heavily on that in the classroom they'll miss out on the social aspect.

Vicki agreed and shared that she was hopeful teachers could mitigate these concerns by making device use interactive. She said, "If there is a way to make it interactive I think that would be good too because you can kind of get the social aspect."

Some caregivers reported problematic behaviors that were a direct result of using technology, such as their child expressing anger when screen time ended. Camila shared, "For a while they were on it a lot. And they were being really naughty when they got off...they were lashing out." Caregivers were uncertain about their efforts to minimize these types of behavior issues. At times, they reported, they would deny their child access at all, until the child could "handle" it.

On the other hand, some caregivers assumed devices were being used as rewards for behavior in their child's classroom. Rachel, for instance, shared, "The (tablets) were definitely used at (school) as a reward. It was time the kids earned. And, I didn't like that." Her involvement in the school as a volunteer and substitute teacher helped her glean this insight. She further divulged, "I've seen the teachers say, 'If you guys are really good and quiet in the hallway, then after lunch we will have (tablet) time."”. 
Sophia described how using tablets as rewards interfered with her son's school-based therapies. Her son had to leave the classroom each day for speech and occupational therapies and these times coincided with tablet time. $\mathrm{He}$ missed that time and was quite upset by it. Acknowledging the teacher could not rearrange the schedule around one child, Sophia felt it interfered with her son's therapy goals. Sophia said, "It was a really big problem. And so that's an issue when the screens are interfering with the other learning that needs to happen. And, how do you explain that to a five-year-old?".

Another developmental concern of caregivers was that traditional classroom learning was overridden by technology use. Rachel worried about her child missing out on fine motor skills that are typically developed in kindergarten. She felt her kindergartener's fine motor skills might be lacking. She shared, "They're five and six. They need to be developing fine-motor skills. Pushing buttons is not developing fine-motor skills. I'm noticing that his fine motor skills are behind where his sisters were at this age." Kelly also noted that she felt too much classroom tablet use might inhibit her child's "listening skills." She noted, "I wouldn't want him to miss out on listening skills. And engaging with his peers and his teachers. To be able to be social."

\section{Increasing Communication Fosters Partnerships}

Collectively, caregivers were concerned over the level of communication they received from schools regarding children's tablet use. Likely, in part, due to the overwhelming nature of the beginning of a school year, caregivers mentioned they received little to no notice about the schools' tablet program. Kelly shared, "I don't know if I was fully aware. I was also just a few months postpartum. So, I might have received a notice... but it came in one ear and out the other." Likewise, other caregivers remembered very little about communication they received. In response to Kelly's comment, Vicki said, "I don't know if I formally got information... You might not have gotten anything."

There was also some confusion about the tablets being sent home mid-year. Some schools within the district sent the tablets home over winter break, while others chose not to do so. Among participants, there were three whose child had brought the tablets home over break. Those caregivers shared that they were given little to no notice to prepare. This frustrated Rachel:

Yeah, there was nearly zero communication about the ... tablets. 'We are doing this great study with (the university). We're going to give the kids tablets and then they'll bring it home at the end of the school year.' And, then at winter break the tablets came home. 'Um, why did you bring this home?'
Similarly, communication was limited when tablets came home on the last day of school. Caregivers were confused about whether data was still being collected from tablet use. Moreover, some caregivers received information on how to reset the device, to clear it of data used in the study, while others did not recall getting that information. There was collective confusion regarding which steps, if any, caregivers should take for their children's at-home tablet use.

While caregivers expressed disappointment in insufficient communication, they also shared ways schools might improve disseminating information. Multimodal communication, such as email, and advanced notice were two ideas caregivers had to improve communication. Caregivers expressed that multimodal communication would help ensure caregivers received information. Brandon stated, "But, it still was the first time I had any communication via email. Which would be way preferable to a piece of paper in a backpack." Sherida reiterated this notion by saying, "you know the papers don't always make it home so. It comes to my phone so. So, you know, every day I could check it."

In addition to multimodal communication, caregivers expressed the need for notice when schools want to send home a device. Rachel recalled being perturbed because the tablet unexpectedly came home the afternoon of winter break. Upon picking up their son on their way to visit family, they were surprised to see the tablet. They had planned to have a "no-tech" trip, but their child's excitement over bringing the tablet home threw a wrench in their plans. She shared, "Forewarning... would have been really nice."

Caregivers also expressed they would like more insight pertaining to their child's classroom tablet use. Specifically, they were interested in the amount of time their children were engaged with the tablets as well as what types of classroom instruction it potentially replaced. Collectively, participants conceded that they had little knowledge about how the tablets were used in classrooms. In one instance, Rachel said she was frustrated with the uncertainty of how to balance her child's screen time at home with his school technology use. Similarly unsure, Erin explained:

But with school, and recognizing, 'Oh, that screen is up there all the time.' And now there's this tablet that he's talking about. I don't know if the screen just fills a lot now. And I don't know what the differences are between the different types of screens. ...It made me wonder if he watches TV at home is he getting six hours of screen time. What does this actually look like? In terms of how does it count?

Caregivers' responses indicated a desire for more information from schools about the amount of screen time their children had at school.

Caregivers also wanted to know how screens were used in classrooms. Some caregivers visited their child's school 
periodically, while others relied on information from their child or their teachers. In one instance, Sophia indicated she felt screens in her child's classroom were used as more of a "babysitter" than for instruction. When visiting, she said, "One of my concerns is I don't always see that the screens have an educational purpose. And there seems to be just a cartoon on." Similarly, Erin expressed that she thought her son's teacher did not put a lot of emphasis on the tablets. "She told me at that final conference that the tablets she, maybe like 20 min a day.... She didn't really push the tablets so much." Erin was not as bothered by the constant use of the classroom SMART board as it was more of a "collective" classroom tool. Vicki volunteered frequently in school and had seen tablets used frequently in kindergarten classrooms. She shared how she had observed children playing games on tablets, but was unsure of any curricular goals. Vicki said she would like to make sure classrooms have "some type of clear curriculum or instruction around it instead of just saying spend ten minutes playing on this math app."

Caregivers also wanted to learn how to translate tablet use to at-home learning. They indicated they would like to hear from teachers about how they might build on learning at home by either reiterating teachers' vocabulary or encouraging their children to use classroom learning apps. Erin found it helpful when she was able to echo classroom language to her son about his reading journal. Similarly, she felt that she could do this with more information from the teacher about tablet use in the classroom. Erin said, "Maybe she shares how she instructs the use of the tablet. It's so much easier if I can just echo the language that she uses."

Caregivers also craved ideas for apps and electronic learning. For example, Kelly suggested that a newsletter on the apps used in the classroom would be helpful. She said, "A one-pager could fulfill that for us. 'Here are the seven apps that we are using in the classroom. This app is called this. Here's what it does. Ask your child about A, B, C.' And then, I would feel like, 'Oh good. I have a tool with to engage with my son about how they've been using this app in the classroom." Camila agreed and felt that if the school would share information on this topic, she would be more inclined to help her child use it for learning. She said, "I feel like even if there was just a small packet sent home of ideas of what caregivers and kids together can do with the tablets. Because otherwise you just assume they can watch and play these games when really you could be doing something with them. Just like in class." Caregivers' requests for information on how tablets are used in classrooms were simple and based on their desire to complement instruction within the home as well as to better know how to manage screen time in the home.

\section{Caregivers Place Trust in Schools}

While caregivers expressed a lack of information on classroom tablet use, they overwhelmingly emphasized a lot of trust in their children's schools and teachers. Even when questioning the motives behind tablet use in instruction, they consistently followed up with how they trusted the schools and teachers to make the best instructional decisions for their children. For example, when discussing her reasoning behind not checking the settings on the tablet, Rachel expressed she did not feel it was of high priority as she trusted the school. She said, "It came from school. It must be okay." Additionally, Sophia further reiterated that point by saying, "Like, it came from school. We think it's fine."

Additionally, caregivers expressed their trust in teachers to make sound instructional decisions about tablet use within their children's classrooms. While discussing device use in classrooms, caregivers collectively described how they trusted teachers to ensure constructive use of technology for learning. Camila said, "I just assumed, which maybe I shouldn't, but. I just kind of assumed that if they're allowing it in the classroom, it's somewhat structured. So, there's got to be hopefully a learning aspect of. It's not just like, 'Here's a tablet. Sit down. And do whatever."

\section{Discussion}

This study substantiated the complexities of mobile device use in early childhood classrooms. Our findings shed light on the multifaceted components of this relatively new, but quickly growing trend. As Bronfenbrenner's (1994) theory suggests, it is important to consider not only the home and school contexts as separate spaces for learning and development, but also to consider their influence on each otheri.e., two micro level contexts interacting at the meso level. Considering how many districts now issue devices that go back and forth with children between home and school, it is fundamentally important that we understand caregiver perspectives on these types of programs and how home and school may work together to best support children's educational device use.

Caregivers' remarks documented in this study exemplified the complexities among children's technology use for learning, in and out of school. Findings revealed caregivers' mixed feelings about navigating a confusing technology environment. They shared perceived benefits of one-to-one devices, but also shared fears and concerns about young children's device use. Despite these mixed feelings, there was one thing caregivers were certain of: they wanted more communication so that they could be better partners in their children's education. Caregivers wanted to learn more about how tablets were used in their 
children's classrooms, thus strengthening a partnership with teachers. Additionally, they desired to know how they might translate classroom device use to at-home learning.

Many of the caregivers' mixed feelings stemmed from their uncertainty about how to best support their children's technology use at home, which school districts might alleviate with improved communication. As Epstein (1987) explains, in the early years, family and school spheres overlap significantly, thus it is important for schools to share learning responsibilities with families. This includes informing caregivers of classroom practices and providing ideas for ways they might support their children at home. Our findings suggest that schools might empower caregivers by providing explicit information about children's technology use in the classroom. Caregivers' requests were uncomplicated in terms of topics and modes. They wanted more information on how the devices were used in classrooms and for how long. They also expressed interest in learning ways they might "mirror" how teachers use devices. By delivering more information about classroom technology use, teachers might alleviate caregivers' uncertainty about balancing at-home use. Additionally, it would give them ideas about how they might complement classroom instruction using tablets. Caregivers' trust in schools and their desire to support their children's teachers highlight pathways for schools to foster positive partnerships with families.

Viewing caregivers as shared partners (Epstein, 1987) with schools, this study's findings provide important information schools can use to help foster positive home-school connections. Caregivers consistently mentioned that they trust their schools' decision making, but also expressed several ways in which schools might improve family communication around children's tablet use. The home-school communication requests caregivers expressed could likely mitigate their concerns, as well as helping them perceive themselves as partners with the school. Overall, these findings align closely with the recommendations put forth by NAEYC and the Fred Rogers Center for intentional classroom technology use (2012), but also point to ways schools might strengthen family partnerships around technology.

\section{Implications and Recommendations}

Our findings about caregivers' interest in partnering with schools and desire for more communication point to several concrete steps that both schools and caregivers can take towards supporting children's learning with new devices. Thus, in this section, we render the study's findings into recommendations for both families and schools to help strengthen communication between them, thus strengthening the partnership and fostering positive outcomes for children.

\section{Recommendations for Schools}

It is important for schools to be aware that caregivers experience a lot of uncertainty on how to navigate their children's technology use for learning. Schools implementing new technology programs should keep families informed about their children's technology use. Opening lines of communication between schools and families will help both parties feel they are sharing the care of the children. This, in turn, will help caregivers support children's learning at home, thus alleviating some of the uncertainty they feel when it comes to technology. We know schools are burdened with immense responsibility and a deluge of information that must be communicated with caregivers, but because of the concerns about technology use-and especially overusethat caregivers are dealing with today, when it comes to new technology programs, this communication piece cannot be overlooked. Consideration of the following suggestions may help schools improve communication with caregivers around technology integration.

Provide multimodal forms of communication. Including electronic and paper copies of materials will help reach more families.

Help families understand how devices are used within classrooms, such as the amount of screen time and for which activities. This might be achieved at caregiverteacher conferences, an open house, or a newsletter. Provide families with ideas about how to use mobile devices for learning at home. These might include educational apps or activities or ways teachers recommend using devices for learning.

Consider equity issues in terms of caregivers' access to resources and understanding of how to partner with schools.

\section{Recommendations for Families}

While our participants spoke mostly about what they would like to see from schools, the home-school connection is very much a two-way partnership (Epstein, 1987). Families can assist schools in strengthening communication about technology integration by voicing questions and concerns. The following are suggestions for caregivers:

When there is technology integrated into classrooms, caregivers might consider asking teachers to provide details about how often and how much the technology is used.

If caregivers feel communication is limited or information is "getting lost in translation," they should feel comfortable asking for that information.

Instead of waiting for schools to send information about how to use technology at home for learning, 
caregivers could consider taking the initiative to seek the information from the schools. This might be done by sending a brief email or setting up a meeting.

Caregivers, too, are inundated with a deluge of parenting recommendations, and we acknowledge that there are cultural disparities in caregivers' level of comfort in reaching out to schools and in understanding the nuances of technology use. However, even just a handful of caregivers within a school or classroom taking these steps, might result in more information shared, thus benefitting all children and caregivers involved.

\section{Conclusion}

This study sought to explore caregivers' perceptions of how a school district's one-to-one device initiative impacted their children in classrooms and at home. Findings emphasize the uncertainty caregivers face regarding using mobile devices for early learning. Navigating technology use for early learning is quite complex, and this study contributes to the field by validating the need for shared responsibilities among schools and families. Schools can strengthen family partnerships by improving communication centered on children's technology use, leading to more seamless and beneficial classroom technology integration.

Acknowledgements The authors thank the Lansing School District, the College of Communication Arts \& Sciences, the College of Education, and WKAR for their facilitation of this research.

Funding This work was supported by the National Science Foundation under Grant No. 1744202. Any opinions, findings, and conclusions or recommendations expressed in this material are those of the authors and do not necessarily reflect the views of the National Science Foundation.

Data Availability Not applicable.

Code Availability Not applicable.

\section{Declarations}

Conflict of interest The authors have no relevant financial or non-financial interests to disclose.

Ethical Approval This study was approved by Michigan State University's Institutional Review Board and was performed in accordance with the ethical standards as laid down in the 1964 Declaration of Helsinki and its later amendments.

Consent to Participate Informed consent was obtained from all individual participants included in the study.

\section{References}

Aladé, F. \& Donohue, T. (2020). Embracing the new normal: parental attitudes towards children's mobile device use at home and at school. Paper presented at the annual meeting of the International Communication Association, held virtually due to COVID-19.

Bentley, K. (2021). Too much screen time in schools? GovTech. https://www.govtech.com/education/news/too-much-screentime-in-schools.html

Beschorner, B., \& Hutchison, A. C. (2013). iPads as a literacy teaching tool in early childhood. International Journal of Education in Mathematics, Science and Technology, 1(1), 16.

Blackwell, C. (2014). Teacher practices with mobile technology: Integrating tablet computers into the early childhood classroom (Vol. 7, pp. 1-26). Nova Science Publishers.

Blackwell, C. K., Lauricella, A. R., \& Wartella, E. (2016). The influence of TPACK contextual factors on early childhood educators' tablet computer use. Computers \& Education, 98, 57-69. https://doi.org/10.1016/j.compedu.2016.02.010

Blackwell, C. K., Lauricella, A. R., Wartella, E., Robb, M., \& Schomburg, R. (2013). Adoption and use of technology in early education: The interplay of extrinsic barriers and teacher attitudes. Computers \& Education, 69, 310-319. https://doi.org/10. 1016/j.compedu.2013.07.024

Bronfenbrenner, U. (1994). Ecological models of human development. In T. Husen \& T. N. Postlewaite (Eds.), International Encyclopedia of Education (2nd ed., Vol. 3, pp. 1643-1647). Pergamon Press.

Brown, S. (2016). Young learners' transactions with interactive digital texts using e-readers. Journal of Research in Childhood Education, 30(1), 42-56. https://doi.org/10.1080/02568543. 2015.1105887

Cavanagh, S. (2018, January 18). Snapshot of K-12 Tech Landscape: More Districts Reach 1-to-1, But Equity Gaps Persist. Market Brief. https://marketbrief.edweek.org/marketplace-k-12/snaps hot-k-12-tech-landscape-districts-reach-1-1-equity-gaps-persist/

Chassiakos, Y. L. R., Radesky, J., Christakis, D., Moreno, M. A., \& Cross, C. (2016). Children and adolescents and digital media. Pediatrics. https://doi.org/10.1542/peds.2016-2593

Cingel, D. P., \& Krcmar, M. (2013). Predicting media use in very young children: The role of demographics and caregiver attitudes. Communication Studies, 64(4), 374-394. https://doi.org/ $10.1080 / 10510974.2013 .770408$

Dolan, J. E. (2016). Splicing the divide: A review of research on the evolving digital divide among K-12 students. Journal of Research on Technology in Education, 48(1), 16-37. https:// doi.org/10.1080/15391523.2015.1103147

Epstein, J. L. (1987). Toward a theory of family-school connections: Teacher practices and parent involvement. In K. Hurrelmann, F. X. Kaufmann, \& F. Lasel (Eds.), Social intervention: Potential and constraints (pp. 121-136). Walter de Gruyter.

Epstein, J. L. (2018). School, family, and community partnerships: Preparing educators and improving schools. Routledge.

Flewitt, R., Messer, D., \& Kucirkova, N. (2015). New directions for early literacy in a digital age: The iPad. Journal of Early Childhood Literacy, 15(3), 289-310. https://doi.org/10.1177/ 2F1468798414533560

Gao, Lafortune, and Hill. 2020. "Who is losing ground with distance learning in California?" Public policy institute of California. https://www.ppic.org/wp-content/uploads/who-is-losingground-with-distance-learning-in-california-october-2020.pdf

Guernsey, L., Levine, M., Chiong, C., \& Severns, M. (2012). Pioneering literacy in the digital Wild West: Empowering caregivers and educators. New America Foundation \& Joan Ganz Cooney Center. 
Herrera, N. A. (2020). Inherited digital divide: How does parents' education influence the way in which their offspring employ the internet for their own benefit? 60. https://pure.tue.nl/ws/porta lfiles/portal/163402016/MSc_thesis_report_Arrazola_Herrera.pdf

Judge, S., Puckett, K., \& Bell, S. M. (2006). Closing the digital divide: Update from the early childhood longitudinal study. The Journal of Educational Research, 100(1), 52-60. https://doi.org/10.3200/ JOER.100.1.52-60

Krueger, R. A. (2014). Focus groups: A practical guide for applied research. Sage Publications.

Lauricella, A. R., Wartella, E., \& Rideout, V. J. (2015). Young children's screen time: The complex role of parent and child factors. Journal of Applied Developmental Psychology, 36, 11-17. https:// doi.org/10.1016/j.appdev.2014.12.001

Lissak, G. (2018). Adverse physiological and psychological effects of screen time on children and adolescents: Literature review and case study. Environmental Research, 164, 149-157. https://doi. org/10.1016/j.envres.2018.01.015

Lu, Y., Ottenbreit-Leftwich, A. T., Ding, A., \& Glazewski, K. (2017). Experienced iPad-using early childhood teachers: Practices in the one-to-one iPad classroom. Computers in the Schools, 34(1-2), 9-23. https://doi.org/10.1080/07380569.2017.1287543

NAEYC, \& Fred Rogers Center. (2012). Technology and interactive media as tools in early childhood programs serving children from birth through age 8 . joint position statement. https://www.naeyc.
org/sites/default/files/globally-shared/downloads/PDFs/resources/ position-statements/ps_technology.pdf

Palaiologou, I. (2016). Teachers' dispositions towards the role of digital devices in play-based pedagogy in early childhood education. Early Years, 36(3), 305-321. https://doi.org/10.1080/09575146. 2016.1174816

Patton, M. Q. (2002). Qualitative interviewing. qualitative research and evaluation methods (pp. 339-428). Sage Publications.

Power, J. R., Musgrove, A. T., \& Nichols, B. H. (2020). Teachers bridging the digital divide in rural schools with $1: 1$ computing. Rural Educator, 41(1), 61-76. https://doi.org/10.35608/ruraled.v41i1. 576

Wilkinson, S. (1998). Focus group methodology: A review. International Journal of Social Research Methodology, 1(3), 181-203. https://doi.org/10.1080/13645579.1998.10846874

Winther, D., \& Byrne, J. (2020, April 7). Rethinking screen-time in the time of COVID-19. UNICEF Office of Global Insight \& Policy. https://www.unicef.org/globalinsight/stories/rethi nking-screen-time-time-covid-19

Publisher's Note Springer Nature remains neutral with regard to jurisdictional claims in published maps and institutional affiliations. 